\title{
A REFORMA PROCESSUAL PENAL DE 2008 E A EFETIVAÇÃO DOS DIREITOS HUMANOS DO ACUSADO
}

\author{
Ludmila Mendonça Lopes Ribeiro, Igor Suzano Machado e Klarissa Almeida Silva
}

THE CRIMINAL PROCEDURAL REFORM OF 2008 AND THE

EFFECTIVENESS OF THE DEFENDANT'S HUMAN RIGHTS

\section{RESUMO}

ESTE ARTIGO BUSCA AVALIAR EM QUE MEDIDA OS DIREITOS humanos do aCusado, preVistos na CONSTITUIÇÃo Federal, ESTÃo SENDO AFETADOS PELAS LEIS 11.719/08 E 11.689/08, AS QUAIS, EM CONJUNTO, PROMOVERAM UMA AMPLA REFORMA do Código de Processo Penal. A primeira alterou a FORMA DE PROCESSAMENTO DOS CRIMES COMUNS E A SEGUNDA, A FORMA DE PROCESSAMENTO DOS CRIMES DOLOSOS CONTRA A VIDA. Nosso estudo fol realizado a partir do (1) CONTRAPONTO DE TAIS REGRAS COM O PRECEITO CONSTITUCIONAL DE RESPEITO AOS DIREITOS HUMANOS; E (2) DA ANÁLISE DE JULGADOS PRODUZIDOS COM MENCÇÃO A ESSAS LEIS NO PERÍODO COMPREENDIDO ENTRE SETEMBRO DE 2008 E SETEMBRO DE 2009. OS RESULTADOS DA PESQUISA INDICAM QUE A REFORMA REALIZOU UMA APROXIMAÇÃO ENTRE AS LEIS PROCESSUAIS PENAIS (DATADAS DA DÉCADA DE 1940) E O PRECEITO INSERIDO NA CONSTItUIÇÃo Federal de RESPEITO AOS DIREITOS HUMANOS, AMPLIANDO A SINTONIA ENTRE ESSAS DUAS ORDENS NORMATIVAS NO BRASIL. ESSA ALTERAÇĀO OCORRE EM CONSONÂNCIA COM MUDANCAS RECENTES NA CULTURA JURÍDICA DO PAÍS, QUE BUSCAM, JUSTAMENTE, EFETIVAR O MODERNO ENTENDIMENTO DE DIREITOS HUMANOS CONSAgRADO NO TEXTO CONSTITUCIONAL. NO ENTANTO, AINDA RESTAM CASOS NEBULOSOS, CUJA COMPATIBILIZAÇÃO ENTRE AS LEIS PROCESSUAIS E O TEXTO CONSTITUCIONAL CABERÁ PRIMORDIALMENTE À ATIVIDADE JURISDICIONAL, ESPECIALMENTE AFETADA POR DIMENSÕES OUTRAS DA CULTURA JURÍDICA BRASILEIRA, COMO A SUPREMACIA DO INTERESSE DO ESTADO SOBRE OS INTERESSES DAS PARTES.

\section{PALAVRAS-CHAVE}

DIREITOS HUMANOS; PROCESSO PENAL; JURISPRUdÊNCIA; REFORMA DE 2008.

\section{ABSTRACT}

THIS ARTICLE EVALUATES IN WHICH EXTENSION THE HUMAN RIGHTS OF THE ACCUSED OF A CRIME, GUARANTEE BY THE FEDERAL CONSTITUTION, HAVE BEEN AFFECTED BY LAWS 11.719/08 AND 11.689/08. TOGETHER, THESE LAWS PROMOTE A COMPREHENSIVE REFORM OF THE CRIMINAL PROCEDURAL CODE. THE LAW 11.718/09 CHANGED THE TRIAL APPLIED FOR COMMON CRIMES AND THE LAW 11.689/08 CHANGED THE TRIAL APPLIED FOR CRIMES AGAINST LIFE. THEREFORE, WE CARRIED OUT THIS STUDY FROM (A) SUCH RULES OF COUNTERPOINT WITH THE IDEA OF HUMAN RIGHTS INSERTED IN THE CONSTITUTION AND (2) ANALYSIS OF THE DECISIONS THAT REFERENCE THESE LAWS AND WERE PUBLISHED BETWEEN SEPTEMBER 2008 AND SEPTEMBER 2009. THE RESULTS OF THIS RESEARCH INDICATE THAT THE REFORM CARRIED OUT A RAPPROCHEMENT BETWEEN THE PENAL LAWS (DATED FROM 1940) AND THE

CONSTITUTIONAL PRECEPTS OF HUMAN RIGHTS, EXTENDING THE LINE BETWEEN THESE TWO NORMATIVE ORDERS IN BRAZIL. THIS CHANGE HAPPEN UNDER OTHER RECENT CHANGES IN THE LEGAL CULTURE OF THE COUNTRY, WHICH SEEKS PRECISELY TO ACCOMPLISH THE MODERN UNDERSTANDING OF HUMAN RIGHTS ENSHRINED IN THE CONSTITUTION. HOWEVER, SOME CASES REMAIN WITHOUT A CLEAR UNDERSTAND REGARDING WHICH PROCEDURE MIGHT BE APPLIED. THUS THE RECONCILIATION OF THE PROCEDURAL LAWS AND THE CONSTITUTION WILL BE RESPONSIBLE PRIMARILY FOR JURISDICTIONAL ACTIVITY. THESE ARE ESPECIALLY AFFECTED BY OTHER DIMENSIONS OF THE BRAZILIAN LEGAL CULTURE, AS THE SUPREMACY OF STATE INTERESTS OVER THE INTERESTS OF THE PARTIES.

\section{KEYWORDS}

HUMAN RIGHTS; CRIMINAL PROCEDURE; JURISPRUDENCE; REFORM OF 2008. 


\section{INTRODUÇÃO}

A proposta deste artigo é estruturar uma discussão sobre a consonância existente entre o moderno entendimento dos direitos humanos e o funcionamento do sistema de justiça brasileiro. Como ponto de análise empírica tem-se as mudanças operadas pela reforma do processo penal, que foi realizada pelas Leis 11.719/08 (que alterou a forma de processamento dos crimes comuns) e 11.689/08 (que alterou a forma de processamento dos crimes dolosos contra a vida). Assim, neste artigo pretende-se discutir o impacto que a reforma legislativa do processo penal brasileiro tem operado sobre os direitos humanos a partir do (1) contraponto de tais regras com o preceito constitucional de respeito aos direitos humanos; e (2) da análise de julgados produzidos com menção a essas leis no período compreendido entre setembro de 2008 e setembro de 2009.

Esse problema é de peculiar importância, dado o entendimento de que a composição normativa do Estado brasileiro contemporâneo se funda na plena incorporação do conceito de direitos humanos, tal como inserido na Declaração Universal dos Direitos do Homem de 1948. Contudo, nem sempre a ação dos aparelhos que compõem o sistema de justiça criminal deste país ocorre dentro desse entendimento.

No contexto da discussão que se pretende empreender, é importante destacar que os juízes não aplicam da mesma forma determinadas leis e que, nem sempre, o entendimento das mudanças processadas pela reforma é unânime nesse segmento. Logo, as possibilidades de inovação ou de ausência de previsibilidade são ainda maiores quando se trata de leis publicadas recentemente, cenário em que a doutrina também pode não ter sido capaz de construir posições pacíficas sobre a natureza e a aplicabilidade de alguns institutos introduzidos ou transformados pelas Leis $11.719 / 08$ e $11.689 / 08 .^{1}$

Em um cenário como esse, cabe aos tribunais acionados em cada caso se posicionarem em relação aos questionamentos das partes sobre a forma como os juízes vêm aplicando os novos procedimentos penais. Deste modo, a análise de tais decisões auxilia o conhecimento dos momentos em que os magistrados consideram pertinente a aplicação dos novos institutos, bem como as ocasiões em que, na visão desses operadores, os novos procedimentos devem ser rechaçados.

A pergunta que se buscou responder com essa análise foi "em que medida os direitos humanos do acusado, previstos na Constituição Federal, estão sendo afetados pelas Leis 11.719/08 e 11.689/08 e suas interpretações jurisdicionais”. Tal como destacado por Clifford Geertz (2002), o Direito é um saber local, caracterizado com base em uma sensibilidade jurídica específica, que, por sua vez, conforma culturas jurídicas específicas, dentro das tradições jurídicas conhecidas. Isso significa que, para entender os possíveis impactos que as novas leis possam gerar sobre a própria efetivação da ideia de direitos humanos, é necessário compreender como essa expressão surge no cenário nacional. 
Para a realização deste estudo, este artigo encontra-se dividido em três seções, além da introdução e da conclusão. Na primeira seção, procura-se apresentar a trajetória de construção do entendimento que se possui do termo "direitos humanos" no Brasil. A seguir, apresenta-se a relação entre as mudanças operacionalizadas pelas leis $11.719 / 08$ e 11.689/08 e os referidos princípios constitucionais correlatos a elas, que consagram determinados direitos humanos no Brasil. A doutrina e a jurisprudência relacionadas a tais legislações servem como ponto de sustentação empírica do argumento que se pretende demonstrar. Por fim, são apresentadas as conclusões.

\section{Direitos humanos no Brasil: VÁRIAS ACEPÇÕes À GUISA DE EFETIVAÇÃo?} De acordo com Piovesan (2005), tal como realçado por Bobbio (1988), os direitos humanos não nascem todos de uma vez nem de uma vez por todas e, assim, seguindo o pensamento de Arendt (1979), é possível afirmar que os direitos humanos não são um dado, mas algo construído, uma invenção humana em constante processo de construção e reconstrução. Os direitos humanos compõem, portanto, um constructo axiológico, fruto da história de cada localidade de acordo com o espaço que ele é capaz de ocupar em termos simbólicos de luta e ação social.

Entende-se por direitos humanos o conjunto de princípios universalizantes formalizados no contexto do Estado liberal-democrático, tal como ele se desenvolveu no mundo europeu ocidental no curso do século 19, que proclamam como direitos inalienáveis do homem os direitos à vida e às liberdades civis e públicas. Entende-se, ainda, que a efetivação de tais direitos humanos requer ação dos governos no sentido de protegê-los contra qualquer espécie de violação ou abuso (Cardia, Adorno e Poleto, 2003).

\section{i. I A formulação da Categoria direitos humanos no CONTEXto mundial}

No entender de Reis (2006, p. 33), a ideia de que existe um conjunto de direitos inalienáveis que os seres humanos possuem pelo simples fato de serem humanos tem uma longa tradição na história do pensamento. No entanto, é apenas a partir da segunda metade do século 20 que o reconhecimento desses direitos passa a ser afirmado internacionalmente pela elaboração de cartas de direitos, tratados e convenções internacionais, e pela incorporação da temática dos direitos humanos nas próprias legislações internas de diversos Estados Nacionais. Já a disseminação da expressão direitos humanos, tal como entendida na atualidade, ocorreu a partir de três marcos especiais: a Carta de fundação da Organização das Nações Unidas (ONU) em 1945; a carta de fundação do Tribunal de Nuremberg, em 1945-1946; e a Declaração Universal dos Direitos Humanos, em 1948.

A Carta da ONU tem sua importância derivada do reconhecimento da legitimidade da preocupação internacional com os direitos humanos. O Tribunal de Nuremberg 
tem relevância por estabelecer a responsabilidade individual de cada Estado pela proteção de tais direitos. Por fim, a Declaração Universal dos Direitos Humanos destaca-se nesse cenário por enumerar o conjunto de direitos civis, políticos, econômicos e sociais, considerados fundamentais, universais e indivisíveis (Reis, 2006, p. 33). Contudo, é importante salientar que esses marcos possuem reflexos diferenciados dependendo da cultura local em questão, sendo que as razões que levaram os Estados a originalmente comprometerem-se com os direitos humanos variam mesmo entre aqueles que consideram que a Declaração representa um avanço em termos da realização dos ideais mais elevados da humanidade (Reis, 2006).

As análises empíricas da transformação de tais marcos internacionais em diplomas e práticas nacionais denotam que, na maioria dos países signatários da declaração, houve uma disseminação do entendimento mais restrito da própria expressão “direitos humanos", que terminou, em um primeiro momento, equiparada a direitos civis. Em parte, isso ocorreu porque, apesar de a Declaração Universal dos Direitos Humanos (1948) ter reconhecido direitos civis, políticos e sociais, esse documento foi considerado, desde a sua redação, uma tentativa de se garantir a paz mundial, evitando que a intolerância de toda espécie (social, étnica, religiosa) levasse a guerras e, sobretudo, a afrontas às liberdades individuais. Nas primeiras décadas após a sua publicação, foi conferida prioridade à implantação de direitos civis, mas a garantia à integridade física ganhou força entre os anos 1970 e 1980, resultando tanto em grande visibilidade das sistemáticas violações de direitos de dissidentes políticos em muitos países e regimes em todo o mundo, como na emergência de uma rede internacional de organizações não governamentais de direitos humanos.

Esse destaque diferenciado aos direitos civis e políticos é decorrente de dois motivos. Primeiro, porque desde a criação da ONU em 1945, o bloco liderado pelos Estados Unidos advogava que esses direitos deveriam ser enfatizados por serem de aplicação imediata, em detrimento dos sociais e econômicos que seriam mais programáticos. Por outro lado, de 1967 em diante, a ONU passou a atuar na fiscalização e em iniciativas para a proteção dos direitos humanos, por meio de investigações promovidas pela Comissão dos Direitos Humanos e também através da atuação dos diversos comitês específicos estabelecidos pelos diferentes pactos internacionais, que sempre tinham como foco as violações dos direitos civis e políticos.

Como as liberdades civis implicam a obrigação por parte do Estado de articular suas estruturas de maneira que garantam um mínimo de respeito à pessoa humana e à plena justiça em casos de abuso, passou-se a conceder especial importância aos estudos que avaliavam como eram efetivados os direitos de não ser submetido a medidas arbitrárias por parte das autoridades estatais, de ter acesso à justiça, e de ser processado com equidade (Cardia, Adorno e Poleto, 2003).

Na década de 1980, a conjuntura mundial colocou os direitos humanos como tema emergente e, com isso, a comunidade internacional passou a se movimentar no 
sentido de garantir um alargamento pragmático desse conceito, afiançando igual ênfase aos direitos civis, políticos e socioeconômicos (Barroco, 2004). Esse movimento culminou, em 1993, com a Conferência Mundial de Viena sobre o tema, a qual reuniu os 171 países membros da ONU e 813 organizações não governamentais (ONGs); o grande resultado desse evento foi o reconhecimento dos direitos humanos como indivisíveis e que os direitos sociais e econômicos eram tão importantes como os direitos civis e políticos.

Apesar desses diplomas e encontros terem ocorrido no contexto europeu, o que se observa, tal como destacado anteriormente, é uma disseminação dessas ideias e movimentos entre os demais países do mundo, e uma absorção diferenciada do conteúdo dessa expressão. Nesse sentido, Piovesan destaca que:

O processo de universalização dos direitos humanos permitiu a formação de um sistema internacional de proteção desses direitos. Esse sistema é integrado por tratados internacionais de proteção que refletem, sobretudo, a consciência ética contemporânea compartilhada pelos Estados, na medida em que invocam o consenso internacional acerca de temas centrais dos direitos humanos, fixando parâmetros protetivos mínimos. Nesse sentido, cabe destacar que até 2003 o Pacto Internacional dos Direitos Civis e Políticos contava com 149 Estados-partes, o Pacto Internacional dos Direitos Econômicos, Sociais e Culturais contava com 146 Estados-partes, a Convenção contra a Tortura contava com 132 Estados-partes, a Convenção sobre a Eliminação de Todas as Formas de Discriminação Racial contava com 167 Estados-partes, a Convenção sobre a Eliminação de Todas as Formas de Discriminação contra a Mulher contava com 170 Estadospartes, e a Convenção sobre os Direitos da Criança apresentava a mais ampla adesão, com 191 Estados-partes. O elevado número de Estadospartes desses tratados simboliza o grau de consenso internacional a respeito de temas centrais voltados aos direitos humanos (Piovesan, 2005, p. 2).

A partir dos anos 1990, tem-se o entendimento de que os direitos humanos precisam ser tratados como um conjunto abstrato de princípios de justiça que podem (ou não) ganhar concretude nos diferentes contextos culturais a partir tanto da edição de diplomas de alcance nacional, como da assinatura de tratados internacionais sobre o tema. A análise desses documentos parece demonstrar a tentativa, em um primeiro momento, de se incorporar o entendimento dos direitos humanos como um catálogo ou uma ajuda ao desenvolvimento humanitário dos países pobres, permitindo que estes, valendo-se do exemplo das sociedades mais "avançadas", queimem etapas em seu processo de desenvolvimento moral, encurtando o tempo de sofrimento da população que ainda está privada do acesso aos direitos “universais” (Costa, 2005). 
Após a era Bush e a Guerra do Iraque ficou evidente que não cabe ao Atlântico Norte ensinar às sociedades "subdesenvolvidas" como modernizar o seu sistema de crenças, valores e atitudes na seara dos direitos humanos. Em cada país, em razão do próprio saber local, os ecos dessa expressão podem ser diferenciados e, com isso, replicar modelos pode gerar mais problemas do que contribuir para o desenvolvimento das populações locais. Afinal, como bem destacam Soares e Guidani: “a despeito de seus vínculos culturais e dos perigos de suas pretensões universalistas, os direitos humanos têm sido muito mais do que a simples promoção de valores liberais, porque são refratados por contextos específicos e assumidos por agentes sociais criativos e críticos" (2010, p. 135).

Em outras palavras, cada sociedade parece internalizar esse conceito e, por conseguinte, as instituições que viabilizam a sua garantia ou a sua prática de maneiras diferenciadas, e de acordo com as suas características culturais, com o seu estágio de discussão sobre o tema ou de institucionalização das características típicas da modernidade. Para compreender o caminho percorrido rumo à institucionalização dos direitos humanos em uma dada sociedade, é importante realizar uma análise sócio-histórica de tal percurso, ou pelo menos revisar os trabalhos produzidos por antropólogos acerca dos dilemas e questões que subjazem a transformação de um conceito propagado internacionalmente em um feixe de regras, instituições e práticas verificado nacionalmente.

\section{I.2 COMO A CATEgoria DIREITOS HUMANOS É APROPRIADA AO CENÁRIO BRASILEIRO}

Conforme já destacamos, os direitos humanos estão intimamente relacionados aos três pilares fundamentais da cidadania, quais sejam: direitos civis, políticos e sociais. Ocorre que, tal como demonstrado por Carvalho (2004), no Brasil, a complexidade dessa questão é eminente em razão de a ordem de constituição de tais direitos ter sido invertida em seu modelo tradicional. Se em análises tradicionais como a de T. H. Marshall (1967) o processo de constituição dos direitos da cidadania é entendido como uma "luta" gradual por direitos civis, políticos e sociais, no Brasil, antes de todos os indivíduos serem livres e iguais (direitos civis) e, por conseguinte, participantes do processo político (direitos políticos), eles tiveram acesso aos direitos sociais.

O problema se tornou ainda mais complexo porque o acesso aos direitos sociais na década de 1940 foram diferenciados de acordo com a profissão que o indivíduo exercia, o que fez com que Santos (1979) denominasse a cidadania brasileira de "cidadania regulada”. Na atualidade, a vinculação com a categoria profissional como mecanismo que viabiliza o exercício de uma cidadania de "melhor qualidade" encontra-se diluída na dimensão "classe social" de origem, esse é o fator que determina a maior ou menor capacidade de um indivíduo em exercer seus direitos. Inclusive, no entender de Souza (2003), esse é o elemento estruturante da sociedade brasileira, sendo ele o que faz com que nessa realidade existam duas classes de cidadãos: os cidadãos plenos, que possuem 
direitos e podem exercê-los; e os subcidadãos, que apesar de possuírem direitos não podem exercê-los do ponto de vista material, por não possuírem as regras e os recursos que viabilizem tal institucionalidade.

Do ponto de vista específico dos direitos civis, e em certa medida dos direitos políticos, dimensões da cidadania mais comumente equiparadas ao conceito de direitos humanos no entender de diversos especialistas, a primeira entrada significativa do discurso relacionado a esse, no Brasil, data de início dos anos 1970 (Zaluar, 2007).

De acordo com Hollanda (2005), a categoria direitos humanos passou a ser mobilizada àquela época por movimentos de esquerda que através do seu uso procuravam (1) pressionar o governo militar a estancar as práticas de tortura e extermínio de militantes políticos; e (2) devolver os direitos civis e políticos àqueles que foram deles privados. Isso equivale a dizer que a luta pelos direitos humanos no cenário brasileiro foi inserida como bandeira da redemocratização, já que durante a ditadura militar a expressão direitos humanos era uma heresia, um ultraje que o Estado punia com violência. Essa expressão era utilizada como mecanismo para a denúncia de torturas, arbitrariedades e assassinatos perpetrados pelo aparato do Estado (Soares e Guidani, 2010).

No contexto da década de 1970, os direitos humanos, para quem os reivindicava, era a proteção aos presos políticos, em sua maioria, oriundos da classe média. Ao longo da década de 1980, esse cenário se transformou e culminou na constituinte de 1988, que engendrou movimentos que viabilizaram a incorporação da categoria direitos humanos como equivalente aos direitos políticos, civis e sociais dentro de uma perspectiva eminentemente universal e totalizante, tal como explicitado por Almeida:

O debate sobre a concepção dos direitos humanos, em uma perspectiva de totalidade (a necessária articulação entre os denominados direitos de primeira geração - civis e políticos, e os chamados de segunda geração - sociais, econômicos e culturais) consubstanciou-se na Constituição Brasileira de 1988, que bem expressou as noções de indivisibilidade e interdependência dos direitos humanos, além de recepcionar tratados internacionais. Com efeito, o Brasil ratificou vários tratados de proteção aos direitos humanos, a partir da promulgação da nova Constituição (Almeida, 2004, p. 61).

Logo, à incorporação dos direitos humanos na carta constitucional, seguiu-se o entendimento de que, com isso, ter-se-iam resolvido as questões relacionadas à efetividade dos direitos da cidadania, especialmente, os civis e políticos. Contudo, o que os estudos e pesquisas de cientistas sociais brasileiros têm demonstrado é que, na prática, tais direitos não são garantidos com equidade, universalmente, e que tampouco é aleatória a assimetria gerada pela distribuição desigual do exercício desses 
direitos. Aliás, no que diz respeito à capacidade do Estado em garantir os direitos civis, segundo Soares e Guidani (2010, p. 125) observa-se que:

Desde a abordagem policial, na ponta do sistema, até o cumprimento da pena, passando pela instrução do inquérito e do processo, e pela prolatação da sentença, a iniquidade reina absoluta. Nada de equidade. Nada de garantias elementares. Os direitos humanos de primeira geração não valem para o Brasil pobre (Soares e Guidani, 2010, p. 125).

Em parte, a afirmação desses autores aponta para o fato de que, no caso brasileiro, como os direitos humanos de primeira geração ainda não foram institucionalizados, grande parte da discussão sobre o tema ainda termina restrita a esses direitos. A questão principal de quem se dedica ao estudo dos direitos humanos na contemporaneidade é como o próprio Estado, a partir de suas regras e instituições, viola os direitos civis, apesar de garantir em boa medida os direitos políticos e sociais.

Essa discussão é de suma importância para o objeto que se pretende analisar uma vez que o Código de Processo Penal é considerado uma legislação que mais viola os direitos do acusado do que os garante. Diante dessa realidade, em crise desde a sua origem e há muito debatida pelos doutrinadores da área, o Código de Processo Penal terminou sendo objeto de vários projetos de reforma que quase nunca se transformaram em realidade, posto que nunca alcançaram a fase de votação no Congresso Nacional. ${ }^{2}$ Em certa medida, todos esses projetos (tanto os que lograram como os que não lograram êxito) tinham um ponto em comum: tornar o sistema de justiça criminal mais célere e mais permeável às demandas dos cidadãos, institucionalizando o ideal de acesso à justiça.

Nesse contexto, outro aspecto a ser ressaltado é o fato de que o uso do termo direitos humanos, em quaisquer searas, mobiliza apoios de "cooperação internacional”. No entender de Almeida (2004, p. 63), isso permite levantar a hipótese de que as demandas por projetos de intervenção ou até mesmo de reforma legal terminam definidas por determinadas exigências internacionais (os chamados acordos ou plataformas de ação internacionais) e não por um diagnóstico social da realidade nacional. Ou seja, tal como destacado por Reis (2006, p. 40), “a retórica dos direitos humanos tornou-se tão forte que as mais diversas propostas políticas tentam de alguma forma expressar sua proposta em uma linguagem compatível com os direitos humanos".

\section{3 A categoria direitos humanos no contexto do processo penal brasileiro}

A reforma processual penal ocorrida em 2008 no Brasil foi orientada pelo Código Processual Penal Modelo para Ibero-América, e elaborada a partir dos preceitos da Convenção Europeia de Proteção aos Direitos do Homem e das Liberdades Individuais 
e da Convenção Americana de Direitos Humanos, ou seja, a partir dos entendimentos europeus e não brasileiros do significado da categoria direitos humanos.

O referido diploma foi redigido em 1988 e possui como características fundamentais a ênfase à dignidade do suspeito e do acusado; a adoção do modelo acusatório (com nítida separação entre as atividades de acusar, defender e julgar); a transparência nos procedimentos; a busca da eficácia do processo (entendida como efetividade das garantias processuais); e a democratização na organização judiciária (Grinover, 2000). As alterações propostas por esse código modelo procuram fazer com que o processo penal latino-americano deixe de possuir um modelo inquisitivo - escrito, burocrático, pouco transparente e moroso -, para alcançar um modelo do tipo acusatório - simplificado, transparente, oral, com o Ministério Público como parte, e tendo como garantias do acusado a ampla defesa, o direito ao silêncio e a presunção de não culpabilidade (Nunes, 2008).

No Brasil, as influências de tal Código devem ser entendidas como o ponto de chegada de uma série de transformações ocorridas na sistemática processual penal nacional nos últimos anos. Isso porque, antes da edição da reforma de 2008, o Código de Processo Penal (CPP) foi objeto de uma série de propostas de alteração que não lograram êxito.

De acordo com Nunes (2008), a primeira proposta foi coordenada pelo professor Hélio Tornaghi; o texto, concluído em 1963, foi entregue ao Ministro da Justiça, João Mangabeira, mas não chegou a ser apresentado ao Poder Legislativo. No ano de 1975, uma nova comissão, coordenada pelo professor José Frederico Marques, foi constituída, sendo elaborado o PL 633/1975. Na Câmara dos Deputados, após estudos realizados por uma Comissão Especial, o projeto de novo CPP teve sua redação final aprovada em primeiro turno, e foi encaminhado ao Senado Federal e posteriormente retirado pelo Poder Executivo. Em parte, a dificuldade em lograr um consenso sobre quais deveriam ser os dispositivos a serem aprovados fez com que o Executivo terminasse por retirar o projeto de pauta. Já na década de 1980, foi composta uma nova comissão coordenada por Francisco de Assis Toledo. Esse grupo manteve as partes fundamentais da codificação anteriormente proposta por José Frederico Marques e apresentou o PL 1.655/1983, que chegou a ser aprovado pela Câmara Federal, mas não foi votado pelo Senado.

Com a publicação da Constituição Federal de 1988, um novo projeto de reforma do CPP foi instituído. No entanto, devido às experiências passadas (de fracassos na edição de um novo Código), foi nomeada uma comissão que deveria propor uma série de leis capazes de alterar pontualmente os problemas mais nevrálgicos do processo penal brasileiro em vez de elaborar um novo código penal. Essa comissão, presidida pelo professor Sálvio de Figueiredo Teixeira, apresentou seis projetos que foram encaminhados para votação no ano de 1994 e que alteravam desde a forma de realização do inquérito policial até a sistemática de contagem dos votos do júri. No mesmo ano, 
contudo, o governo decidiu retirar os projetos da pauta de votação para aperfeiçoálos, dado o entendimento de que esses ainda não se adequavam plenamente aos ideais de um processo penal moderno e garantidor dos direitos humanos, fundamentais ao acusado (Grinover, 2000).

Já ao final da década de 1990, o Ministério da Justiça convidou o Instituto Brasileiro de Direito Processual (IBDP) para apresentar sugestões de aperfeiçoamento dos seis projetos de lei originalmente redigidos pela comissão de 1994. No ano de 2001, depois de vários debates com os mais diversos segmentos da sociedade (como membros de entidades públicas e associações da polícia, da advocacia, do Ministério Público e da magistratura), a comissão do IBDP, coordenada por Ada Pellegrini Grinover, entregou ao MJ sete anteprojetos de lei, cada qual alterando uma dimensão da processualística penal brasileira (Passos, 2008).

Nos anos anteriores a 2008, contudo, a reforma processual penal caminhou muito pouco, sendo recolocada em pauta quando da morte do menino João Hélio, ${ }^{3}$ evento que levou à pressão a edição de uma ampla reforma processual penal que fosse capaz de aumentar a eficiência do sistema de justiça criminal no processamento de crimes graves. Ainda no primeiro semestre de 2007, alguns dos projetos elaborados em 2001 foram finalmente apreciados pelo Congresso Nacional. Como no momento de votação da reforma, o Brasil encontrava-se sob o efeito de outro crime de ampla repercussão (caso Isabella Nardoni), ${ }^{4}$ vários dos projetos de lei lograram aprovação. Foram estes: (1) PL n. 4.203/2001, transformado na Lei n. 11.689/08 - alterando o rito do tribunal do júri -; (2) PL n. 4.205/2001, transformado na Lei n. 11.690/08 - alterando a forma de produção de provas -; (3) PL n. 4.207/2001, transformado na Lei n. 11.719/08 - alterando o rito ordinário (Abramovay, 2008).

A reforma que se analisa na seção seguinte é fruto de um longo caminho percorrido durante, aproximadamente, quarenta anos e que, apesar de diversos estudos e pareceres técnicos, ainda não foi capaz de lograr a edição de um novo Código de Processo Penal. É importante destacar, contudo, que no momento de redação deste artigo encontrava-se em votação em primeiro turno, no Senado Federal, um novo projeto de Código de Processo Penal. O Projeto de Lei do Senado (PLS) 156/09, de autoria do senador José Sarney, é fruto de um anteprojeto elaborado por uma Comissão de Juristas, criada em julho de 2008, logo após a aprovação das leis que são analisadas neste artigo. Ao texto original foram anexadas outras 48 propostas que versam sobre o processo penal. Esses projetos transformaram-se numa proposta única, concluída em dezembro de 2009 pela Comissão Temporária de Estudo da Reforma do CPP, constituída especialmente para análise do assunto.

O PLS 156/09 tem mais de setecentos artigos, e faz uma série de mudanças na atual lei, definindo de maneira mais clara os prazos de tramitação dos processos penais e, ainda, a redução do número de recursos existentes nesse diploma. Estabelece ainda 
a criação do juiz de garantias (um segundo juiz que passaria a atuar como investigador do processo), o que, na visão de alguns especialistas, pode atrasar ainda mais a tramitação de ações criminais. Impõe também a instituição de medidas cautelares aos presos durante o cumprimento da pena, como o monitoramento eletrônico, que seria usado antes mesmo da sentença. Permite ainda a contestação da denúncia pelo réu antes da instauração formal do processo criminal. Outra mudança é a ampliação de circunstâncias que decretam a prisão preventiva, que poderá ser determinada pelo juiz considerando-se apenas a gravidade do crime cometido.

Essas ressalvas são importantes porque esse artigo analisa os problemas, ou as questões, relacionados à consonância entre a reforma de 2008 e a maior efetivação dos direitos humanos no plano nacional, os quais, em certa medida, não parecem ter sido contemplados na reforma atualmente em votação no Senado Federal. Por outro lado, exatamente em razão desse cenário em constante processo de mutação, a Lei $11.719 / 08$ e a Lei $11.689 / 08$ devem ser entendidas como pontos de partida para a consolidação de um sistema de justiça criminal moderno no cenário brasileiro.

Considerando que, de acordo com o novo paradigma que deve reger as práticas jurídicas brasileiras, a legislação infraconstitucional não pode estar em desacordo com o texto constitucional, neste estudo verificamos como, de acordo com as transformações e permanências da cultura jurídica nacional, as novas leis e a ideia de direitos humanos, tal como contempladas pela Constituição Federal de 1988, têm se aproximado ou se afastado, vislumbrando, assim, possíveis reformulações na legislação processual penal em vigor, capazes de torná-la mais adequada ao sistema de garantias dos direitos humanos que são oferecidas ao acusado de cometimento de qualquer crime.

Contudo, tal como destacado por Soares e Guidani (2010, p. 141), as regras legais, quando aplicadas, são expostas a toda sorte de choques e contradições, por isso espera-se que a efetivação das leis supracitadas, ainda que na tentativa de aumentar a consonância entre a legislação infraconstitucional e a constitucional, tenha produzido controvérsias ou, pelo menos, julgados que ilustrem a ausência de entendimento unânime sobre como a justiça pode ou deve ser administrada em uma dada localidade com vistas a dar maior institucionalidade à ideia de direitos humanos. Esse também é um ponto de análise privilegiado por este artigo na medida em que se faz uso da jurisprudência dos tribunais brasileiros como referência empírica para sua argumentação.

\section{A Reforma Processual PENAl de 2008 SOB A ÓPTICA CONSTITUCIONAL E JURISPRUDENCIAL}

A reforma empreendida pelas Leis 11.719/08 e 11.689/08 procurou, simultaneamente, aumentar a celeridade processual e aperfeiçoar o sistema de garantias do acusado tornando o processo penal brasileiro mais democrático. Neste capítulo 
pretende-se salientar os principais afastamentos e aproximações entre as novas leis, e a forma como o conceito de direitos humanos encontra-se inserido na Constituição Federal de 1988 .

A Constituição é uma norma eminentemente principiológica, razão pela qual se faz mister apreciar as novas leis sob o prisma dos princípios e garantias fundamentais nela insculpidos. No entanto, antes de adentrar os princípios constitucionais e suas implicações para a reforma processual penal, é necessário fazer uma breve análise acerca do que podemos tomar como princípios, ou seja, qual a sua conceituação e relevância.

\section{I O PRINCÍPIO CONSTITUCIONAL DE RESPEITO AOS DIREITOS HUMANOS DO ACUSADO}

Depreende-se que a Constituição Federal é a norma paradigma, na qual todas as outras normas devem buscar fundamento e validade. Essa afirmação se revela imperiosa a todos os dispositivos legais, seja qual for a matéria por eles tratada, e ganha especial relevância quando seu escopo é a matéria processual penal, já que esta lida diretamente com a liberdade, direito cujo cerceamento deve ser sempre juridicamente respaldado e fundamentado, sob pena de o ato que o determinou quedar-se eivado de vício insanável.

A análise das alterações trazidas por essa reforma, patrocinada pelas Leis 11.719/08 e 11.689/08, passa obrigatoriamente por saber se elas efetivamente se coadunam com a Constituição, principalmente no que tange aos direitos e garantias fundamentais, matéria cuja relevância é tamanha, que é tratada pela Constituição Federal de 1988, no $\S 4^{\circ}$, inciso IV do seu artigo $60,{ }^{5}$ como cláusula pétrea, que veda a elaboração de Emendas Constitucionais tendentes a aboli-los.

Os direitos e garantias fundamentais do acusado estão positivados, em sua maioria, no $\operatorname{artigo~} 5^{\circ}$ da Constituição Federal. Entretanto, esse rol é apenas exemplificativo, visto que outros tantos são definidos de forma esparsa ao longo dos diversos capítulos do texto constitucional. É possível afirmar que a tutela dos direitos humanos se revelou uma preocupação básica da Constituição de 1988, na medida em que lhe coube expurgar os resquícios do regime de exceção que a antecedeu. Dentre os instrumentos corriqueiros do regime militar, contavam-se as prisões arbitrárias sem garantia de defesa para os acusados, a prática sistemática da tortura, e o desrespeito a outros direitos fundamentais, como a inviolabilidade do domićlílo. ${ }^{6}$

Experiências como essa, brasileira, e especialmente casos europeus anteriores de nazismo e fascismo, levaram à ruptura do Direito com modelos positivistas estritos, isto é, baseados na mera aplicação da lei. Contra uma visão do Direito como conjunto de regras prescritas pelo Legislativo a serem reafirmadas pelo Judiciário surge no campo jurídico um novo afã por trazer à baila princípios de direitos humanos que não podem ser desconsiderados sob nenhuma hipótese.

Mesmo sem reafirmar um pretenso direito natural, derivado de uma natureza humana supostamente fixa e universal, autores da teoria jurídica contemporânea, como Dworkin (2003) e Alexy (2003), passaram a destacar o fato de que qualquer sistema 
jurídico é formado não apenas por regras, mas também por princípios. Em outras palavras, o Direito seria composto não apenas de mandamentos que prescrevem determinadas sanções para determinadas condutas, tornando-as, em consequência, permitidas, obrigatórias ou proibidas, mas também de prescrições mais gerais, sem aplicabilidade imediata, que, no entanto, dão ao conjunto de regras coerência ética mais do que mera sobreposição aleatória.

Dworkin (2003) dá um exemplo descrevendo o caso do neto que mata o avô para receber a herança. O assassino faria jus a essa herança?, questiona o autor. Se partirmos de uma interpretação positivista estrita, em não havendo nenhuma lei que estabeleça como regra a proibição de ser herdeiro o assassino de quem deixa a herança, então se torna obrigatório aceitar que o neto faz jus ao espólio do avô. No entanto, fica difícil aceitar que um sistema jurídico que pune, por exemplo, a fraude, o estelionato e o latrocínio, possa aceitar algo que intuitivamente vai contra a concepção geral do que é justo.

Isso acontece, argumenta Dworkin (2003), exatamente porque um sistema jurídico não pode ser composto apenas de regras. Parece intuitivamente errado que o neto herde a fortuna do avô que ele mesmo assassinou, pois também compõe esse sistema o princípio de que ninguém pode se beneficiar da própria torpeza. Mesmo que esse princípio não seja explicitado em nenhuma lei, a interpretação do ordenamento como um todo coerente permite ao intérprete verificar que esse princípio está ali, informando várias de suas regras para que elas componham um todo coeso e não a mera sobreposição de caprichos legislativos.

Tendo esse arcabouço em vista, pode-se dizer que por princípio tem-se uma estrutura sobre a qual é possível realizar algo, tem-se um ponto de partida, o limiar introdutório dos institutos jurídicos. É neles que se pode buscar validade para as normas. Todavia, como já dito, a revalorização dos princípios de direitos humanos não tem relação com o simples retorno à teoria do direito natural, baseado no inacessível âmago do que nos faz verdadeiros seres humanos. Tais princípios são extraídos do próprio ordenamento e da história institucional da comunidade a que eles se aplicam. Nesse contexto, ganha lugar de destaque a Constituição, como vértice hierárquico do conjunto de normas jurídicas de determinado local.

Partindo da premissa de que o ordenamento jurídico brasileiro também adotou a positivação de princípios de direitos humanos no texto da Carta Constitucional de 1988, a legislação produzida no país deve estrita obediência a essa ordem principiológica, para que não se corra o risco de ter seu intuito desvirtuado, inclusive pelo próprio Poder Judiciário. Daí a importância de, no estudo das alterações produzidas pelas Leis $11.719 / 08$ e 11.689/08, avaliar-se em que medida seus dispositivos vão ao encontro dos ditames da Constituição Federal.

Passa-se, portanto, à análise dos dispositivos previstos nessas leis à luz dos princípios constitucionais que deveriam regê-los, destacando os possíveis acordos e desacordos 
entre essas duas fontes normativas do sistema jurídico brasileiro que precisam, obrigatoriamente, estar em harmonia e em consonância com os entendimentos atuais dos direitos humanos como princípios individuais e indivisíveis.

\subsection{O PROCESSO DE APLICAÇÃO DAS NOVAS LEIS PROCESSUAIS PENAIS:}

PONTOS POLÊMICOS QUE PODEM COMPROMETER A MATERIALIZAÇÃO DOS DIREITOS FUNDAMENTAIS DO ACUSADO

Os princípios norteadores do processo penal encontram-se basicamente no artigo $5^{\circ}$ da Constituição da República Federativa do Brasil. Dentre eles merecem destaque: a dignidade da pessoa humana e o tratamento isonômico; a presunção de inocência; o respeito à integridade física e moral do preso; o devido processo legal; o contraditório e a ampla defesa; o juiz natural; a proibição ao uso de provas ilícitas; a razoável duração do processo; e o tribunal do júri.

O contraponto entre a reforma patrocinada pelas Leis 11.719/08 e 11.689/08 e os princípios constitucionais elencados demonstram que, no geral, as modificações inseridas no processo penal pelas novas leis atuam no sentido de dar maior efetividade aos princípios e garantias constitucionais fundamentais incidentes no processamento criminal.

Como exemplo, tem-se a proibição do uso de algemas pelo réu durante os debates do júri. ${ }^{7}$ Tratava-se de medida atentatória contra a presunção de inocência do réu e, em respeito a essa presunção e em concordância com a preservação da dignidade da pessoa humana na dimensão da integridade física e moral do réu, a reforma atuou no sentido de coibir tal prática, fazendo do uso de algemas pelo réu a exceção e não a regra no procedimento do júri. O que antes era orientação jurisprudencial, com a reforma tornou-se preceito positivado em lei.

O mesmo expediente encontra ainda vetor de funcionamento em outra alteração trazida pela reforma: a que proíbe a referência ao silêncio do réu em seu prejuízo. ${ }^{8}$ Trata-se de mais uma medida visando dar efetividade, no processo penal, a direitos constitucionalmente garantidos, como é o caso do direito do réu ao silêncio, e a princípios de justiça, como a presunção de inocência.

Da mesma forma, a extinção do protesto por novo júri, ${ }^{9}$ a um só tempo, reforça o texto constitucional na ampliação da soberania dos veredictos do júri e na efetivação da garantia da razoável duração do processo. Contudo, essas são as medidas menos polêmicas da reforma, por isso elas têm encontrado amplo respaldo na doutrina jurídica e mesmo nos julgamentos penais.

Outros aspectos dessa reforma são, todavia, bem menos consensuais. Mesmo que busquem justamente a efetivação das garantias constitucionais do devido processo legal, da razoável duração do processo e do direito ao processamento dos crimes dolosos contra a vida pelo júri, tais medidas geram polêmica e talvez requeiram alterações para se adequarem mais estritamente ao texto constitucional. 
A primeira das polêmicas diz respeito ao fim do fracionamento da audiência. ${ }^{10}$ Em tese, uma audiência única facilitaria a ampla defesa, garantiria o princípio da identidade física do juiz, e contribuiria para uma duração razoável do processo. No entanto, há quem levante a hipótese de que a audiência fracionada, possibilitando apreciação parcelada das provas, seja mais propícia para a garantia, especificamente, da ampla defesa, que gozaria de superioridade perante o princípio da identidade física do juiz e do objetivo de maior celeridade no andamento dos processos.

A maioria das discussões relacionadas ao cerceamento de defesa faz menção ao artigo 400, $\S 1^{\circ}$ do CPP, ${ }^{11}$ que foi incluído pela Lei $11.719 / 08$, ao conceder ao juiz a faculdade de deferir ou não a produção de provas, de acordo com a utilidade ou necessidade destas à instrução criminal. Essa situação pode ser exemplificada ${ }^{12}$ pelo Habeas Corpus 74706, julgado pelo TJMT:

HABEAS CORPUS - ATENTADO VIOLENTO AO PUDOR - PRISÃO PREVENTIVA - NECESSIDADE - ASSEGURAR A APLICAÇÃO DA LEI PENAL - CERCEAMENTO DE DEFESA - REQUERIMENTO DE DILIGÊNCIA ESTUPRO PSICOLÓGICO E CONTRA PROVA DE PERÍCIA INDEFERIMENTO - DISCRICIONARIEDADE REGRADA DO MAGISTRADO - ORDEM DENEGADA. 1 - Estando presente prova da materialidade do crime, indícios suficientes de autoria do delito, atrelado à presença de um dos requisitos previstos no artigo 312 do Código de Processo Penal, é o bastante para embasar o decreto preventivo, como é o caso presente, uma vez que o paciente logo após a comunicação dos fatos à autoridade policial evadiu-se do local da culpa, sendo necessária a custódia cautelar para assegurar a aplicação da lei penal. 2 - O deferimento de diligências (prova pericial) na fase do artigo 402 do CPP, com redação da pela Lei n. 11.719/2008, que revogou o disposto no antigo artigo 499 do Caderno Processual Penal, é ato que se inclui na esfera de discricionariedade regrada do magistrado processante, que poderá indeferi-las de forma fundamentada, quando as julgar protelatórias ou desnecessárias, ou ainda sem pertinência com a instrução do processo, nos termos do artigo $400, \S 1^{\circ}$ do CPP. 3 - Ordem de Habeas Corpus denegada.

De fato, existe uma tensão inescapável entre a celeridade processual e a ampla defesa, sendo a duração razoável do processo aquela que consegue equilibrar duas dimensões temporais fundamentais: por um lado, o tempo necessário para que o réu disponha de todos os meios para sua defesa e o Estado disponha dos meios legítimos para alcançar a verdade dos fatos; por outro, o tempo necessário para a finalização mais rápida possível do processo, de forma que a angústia dos envolvidos não se prolongue demasiadamente. Foi o equilíbrio entre essas duas dimensões o objetivo buscado pela reforma quando estipulou novos prazos processuais e novo formato das 
audiências. Entretanto, parece que o resultado não foi alcançado: considera-se em muitos casos que a reforma, ao privilegiar a resolução mais rápida dos processos, prejudicou a ampla defesa do réu e a busca pela verdade do Estado-juiz.

É possível que nunca se alcance plenamente a estabilização aludida. Afinal, qualquer ponto de equilíbrio de um sistema que busca, ao mesmo tempo, a celeridade processual e a ampla defesa permitiria, por um lado, ao réu com perspectivas maiores de ser absolvido acusar o sistema de falta de celeridade e, por outro, ao réu com chances maiores de ser condenado acusar o sistema de desrespeito ao seu direito de ampla defesa. E a previsão constitucional de uma duração "razoável” do processo, dada a vagueza do termo, não resolve o problema.

Outra polêmica que igualmente chamou atenção na análise constitucional e jurisprudencial da reforma diz respeito à positivação do princípio da identidade física do juiz no processo penal. ${ }^{13}$ Se a garantia do devido processo legal é a segurança do processo na forma prevista em lei, desrespeitar as novas diretrizes estipuladas pela Lei 11.719/08, tal como o princípio da identidade física do juiz, deveria significar o desrespeito àquela garantia. No entanto, mesmo contando agora com expressa previsão legal, o princípio da identidade física do juiz não deixou de ser relativizado e desrespeitado. Nesse sentido, cumpre destacar a decisão da Sexta Câmara Criminal do Tribunal de Justiça do Rio de Janeiro acerca do conflito de 280/2009 que afirma:

Conflito negativo de jurisdição, correlato ao princípio da identidade física do juiz; contido no artigo $399 \S 2^{\circ}$ do Código de Processo Penal, na alteração dada pela Lei 11719/2008. Suscitação por magistrada que encerrou a instrução, dando vista para alegações finais, sendo que outro juiz realizou o interrogatório e ouviu uma testemunha, e outra juíza inquiriu outras testemunhas. Parecer ministerial pela rejeição do Conflito. Razão manifesta. Interrogatório efetivado antes da vigência da norma inovadora. Instrução que houve em atos diversos, não por fracionamento decretado, mas ainda dentro do rito pretérito. Contato pessoal do juiz que não se reputa imperioso em se restringindo ao acusado, mas abrangendo as testemunhas arroladas pelas partes. Conjugação que impende ser feita, na espécie, entre o dito dispositivo e o artigo 132 do Código de Processo Civil, aplicável por analogia. Conflito que se desacolhe, dando-se pela competência, acerca da Sentença, da Magistrada que o deflagrou (grifo nosso).

Sem expressa previsão constitucional, essa garantia é reputada menos importante que outras, como a ampla defesa. Por exemplo, caso se entenda que a audiência fracionada é benéfica à ampla defesa do réu (evidentemente sempre que suscitada pela defesa técnica), por mais que isso implique maior probabilidade de o juiz responsável pelo pronunciamento da sentença não ser o mesmo responsável pela coleta 
de provas, o fracionamento deve ser mantido, ainda que sacrifique o princípio da identidade física do juiz.

Diante desse quadro, uma saída para dar maior efetividade ao princípio da identidade física do juiz seria alçá-lo também ao patamar constitucional, exigindo assim maior fundamentação para os casos de inobservância. Melhor seria, talvez, insistir-se na efetivação (e na observância) da sistemática das audiências unas, para que não houvesse possibilidade concreta de desrespeito ao novo princípio.

Outra polêmica que merece igual destaque é a regulação, pela reforma, dos institutos da mutatio libell e da emendatio libelli.

A mutatio libelli é o instituto jurídico aplicável quando se verifica a possibilidade de criar nova definição jurídica do fato após o fim da instrução criminal, em consequência de prova existente nos autos de elemento ou circunstância da infração penal não contida na acusação. Antes da reforma trazida pela Lei 11.719/08, o instituto era aplicado da seguinte forma: o juiz, vendo que a definição jurídica do fato poderia ser diversa daquela apresentada, em decorrência de fatos novos não contidos na denúncia ou queixa, deveria abrir prazo para a defesa se manifestar e produzir provas. $\mathrm{O}$ legislador infraconstitucional quis dar fim às críticas que eram feitas a esse sistema frequentemente atacado por afrontar o princípio do contraditório, segundo o qual não é a parte acusada quem deve inaugurar a instrução dizendo que não cometeu o crime, mas sim a acusação que, após a denúncia, deve apresentar seus elementos probatórios, para que assim seja plena a defesa do acusado.

Após a reforma, em vez de a parte ré ser intimada a "se defender" de decisão interlocutória, intima-se primeiro o Ministério Público - ou o querelante, em caso de queixa - para que este adite ou não a sua denúncia. Com isso, preserva-se a iniciativa acusatória do Ministério Público - retirando-a do juiz que, na sistemática anterior, acabava por invadir competência alheia e desfigurar sua posição imparcial e inerte -, e um processo cujo contraditório envolve efetivamente as duas partes, de acordo com o que cabe a cada uma, isto é, à acusação acusar e à defesa defender, necessariamente nessa ordem. No que tange ao princípio do contraditório, portanto, a reforma ampliou a consonância existente entre as regras processuais e os ditames constitucionais.

Já a emendatio libelli é o instituto regulado pelo artigo $383^{14}$ do CPP que dá ao juiz a possibilidade de classificar o fato imputado ao réu como crime diverso daquele citado na denúncia do Ministério Público, mesmo que isso implique a sujeição do condenado a pena maior. O problema desse instituto está no fato de ele ofender a um só tempo a ampla defesa do réu (por só revelar o crime de que estaria sendo acusado quando da sentença), do juiz natural e do princípio acusatório (por quebrar a imparcialidade do magistrado ao sobrepujar sua inércia), e mesmo do contraditório, já que é decisão do juiz, e não a do Ministério Público, dar ao crime uma nova classificação. 
Se a reforma foi feliz no que se refere à nova redação do artigo 384, que regula a mutatio libelli, realçando os princípios constitucionais do juiz natural e do contraditório, reforçando a inércia do magistrado e aumentando a responsabilidade do Ministério Público no instituto, o mesmo não pode ser dito quanto à redação do artigo 383, que regula a emendatio libelli. Esta sofreu alterações importantes, porém, insuficientes, segundo alguns doutrinadores. ${ }^{15}$ Isto porque a atual redação ainda dá ao juiz um poder muito grande ao permitir que ele altere a classificação do crime sem consulta ao Ministério Público e sem possibilidade de manifestação da defesa.

Segundo o entendimento doutrinário que orientou a reforma, a reclassificação do crime por parte do juiz não ofenderia o contraditório nem a ampla defesa, pois tanto a acusação quanto a defesa focalizariam seus argumentos nos fatos alegados e não no tipo penal definido. Entretanto, como o escopo da defesa não é unicamente negar os fatos imputados ao réu pela acusação, mas também englobar aspectos relativos à tipicidade penal, tem-se que o instituto da emendatio libelli, permanecendo como está, incorreria em vícios constitucionais graves. Por um lado, daria ao juiz - que dando nova tipificação ao crime poderia estipular pena mais grave que a prevista na denúncia -, força acusatória que lhe feriria a inércia, fundamental no que diz respeito ao princípio do juiz natural. Por outro, estreitaria a ampla defesa do réu, que só tomaria ciência do tipo penal de que é acusado quando da emissão da sentença.

Assim, talvez o correto fosse estender à emendatio libelli o mesmo funcionamento da mutatio libelli, retirando sua competência do juiz e transferindo-a ao Ministério Público ou, pelo menos, exigindo que este a aprovasse. Com isso, seria respeitada a inércia do juiz e o processo seria desenvolvido à lógica do contraditório, com a acusação acrescentando nova dimensão à sua denúncia a ser contradita ou aceita pela defesa, para só depois disso ser permitida a manifestação do juiz.

Outra polêmica que merece destaque diz respeito aos problemas relativos à decisão de pronúncia. A reforma, no $\S 3^{\circ}$ do artigo 413, ${ }^{16}$ exigiu expressamente, quando da prolação da pronúncia, a motivação fundamentada por parte do juiz para a decretação ou manutenção da prisão. Com isso, em última instância, o que a legislação procurou impedir foi a decretação automática, ou ainda a manutenção da impossibilidade da liberdade quando esta não se faz necessária -, situação em uma medida cautelar chega a se transformar em mecanismo de antecipação de punição (Bandeira, 2007).

Os problemas de tal mudança estão em duas possibilidades contidas na fundamentação dessa peça: ou ela é muito exígua e rompe a garantia do réu de ter fundamentadas as decisões em seu desfavor, ou ela é demasiadamente ampla e rompe a garantia do réu de chegar ao júri gozando de plena presunção de inocência. Como exemplo do segundo caso tem-se o julgamento do Habeas Corpus N. 84.396 - SP (2007/0129991-5) pelo STJ: 
PROCESSUAL PENAL. HABEAS CORPUS. HOMICÍDIO TRIPLAMENTE QUALIFICADO, SEQUESTRO E CÁRCERE PRIVADO. SENTENÇA DE PRONÚNCIA. EXCESSO DE LINGUAGEM. LEI 11.689/08. NOVO ART. 478 DO CPP. ORDEM PARCIALMENTE CONCEDIDA. 1. Muito embora o STF, recentemente (HC 96.123/SP, Rel. Min. Carlos Brito, julgado em 3/2/09), tenha expressado entendimento no sentido de que, em razão da superveniência da Lei 11.689/08 - que deu nova redação ao artigo 478 do CPP, impossibilitando as partes de fazerem referências à sentença de pronúncia durante os debates -, não mais haveria o interesse de agir das impetrações que alegassem excesso de linguagem, a norma inserta no novo artigo 480, $\S 3^{\circ}$, do CPP permite aos jurados a oportunidade de examinar os autos logo após encerrados os debates. 2. Devem ser excluídos da sentença de pronúncia trechos nos quais o magistrado emite opinião quanto à autoria do crime, pois, de alguma forma, pode, em prejuízo à defesa, influir na convicção dos jurados.

A questão se torna ainda mais complexa com a extinção da figura da prisão em decorrência da decisão da pronúncia, ${ }^{17}$ fazendo com que, se o juiz considerar necessário o recolhimento do réu à prisão para melhor prosseguimento do processo desde que esteja o caso diante dos requisitos cautelares do fumus commissi delicti e periculum libertatis -, ele possa fundamentar essa decisão.

Talvez o melhor fosse que as novas leis estipulassem regras claras para a confecção da pronúncia, evitando sua nulidade tanto pelo excesso quanto pela falta de fundamentação. Por exemplo, a decisão do juiz poderia abdicar de termos próprios, fazendo apenas referência ao discurso utilizado pela acusação. Da mesma forma, as decisões relativas ao encaminhamento do réu à prisão ou à necessidade do uso de algemas durante a audiência poderiam ser exigidas sempre em peças distintas que contivessem em destaque os dizeres de que se trata de medida de ordem processual, sem qualquer relação com a afirmação ou negação da culpa do réu no crime pelo qual está sendo julgado.

A última polêmica diz respeito à simplificação dos quesitos a serem votados pelo júri. Buscando facilitar o julgamento por parte dos jurados, a reforma modificou a formulação dos quesitos a serem votados pelos juízes leigos. Dentre essas modificações, tem destaque a adoção de um quesito único referente à absolvição ou condenação. O problema é que, diante de várias teses absolutórias apresentadas pela defesa, não resta mais possível saber qual delas foi aceita pelo conselho de sentença. Sendo assim, se no modelo anterior, onde se sabia o exato motivo da absolvição, existiam decisões de segundo grau a invadir a soberania do júri, reformando o veredicto unicamente porque não concordavam com a tese escolhida, é possível supor que, sem saber ao certo esse motivo, ficará o réu absolvido ainda mais sujeito à reforma da decisão do júri. Isso representaria ofensa não apenas ao princípio da soberania dos 
veredictos, mas também à plenitude de defesa, já que a simplificação do questionário estaria, indiretamente, lesando o interesse do acusado (Nucci, 1999, p. 164). ${ }^{18}$

\subsection{Pontos Polêmicos das nOvas leis e eficÁcia dos direitos humanos No Brasil}

Os pontos polêmicos da reforma processual penal de 2008, apresentados na seção anterior, revelam que tensões entre a ampla defesa e a razoável duração do processo, ou entre a ampla defesa e o princípio do juiz natural, ou ainda entre a presunção de inocência do réu e a necessidade de fundamentação das medidas de restrição de direitos, têm reduzido a força vinculante das novas leis.

Se for tomado o moderno entendimento do termo direitos humanos - que segundo Kant de Lima (2004) diz respeito à criação de mecanismos capazes de prover tratamento igual aos diferentes, universalizando a aplicação da lei às distintas identidades que se especificam no espaço público -, percebe-se, pela análise dos pontos polêmicos apresentados, que as novas regras ainda deixam ao magistrado uma ampla discricionariedade para implementar regras que implicam, diretamente, nos direitos humanos do acusado. Um dos problemas decorrentes dessa realidade reside no fato de que no Brasil a atualização de regras que se pretendem igualitárias - como deveria ser o caso do excesso de tempo, da identidade física do juiz, da emendatio libelli, da motivação fundamentada da pronúncia, extinção da prisão em decorrência da pronúncia e simplificação da quesitação no tribunal do júri -, é muitas vezes identificada como injustiça, pois sobrepõe um sistema explicitamente igualitário (existente nos regulamentos internacionais e nacionais) a um sistema implicitamente hierárquico (que é a forma como se estruturam as relações sociais no Brasil), de tal modo que a convivência de ambos requer práticas e valores desiguais. Isso significa que, apesar de a regra da lei ser a de tratamento igual aos diferentes, a regra consagrada na prática cotidiana dos tribunais brasileiros é "tratar desigualmente os desiguais”, o que significa, em última instância, dar aos pobres a sua pobreza e aos ricos a sua riqueza.

Por mais que a reforma processual penal tenha sido animada pela efetivação dos direitos humanos previstos no texto constitucional, podendo-se mesmo dizer que não incorreu em nenhum caso de flagrante inconstitucionalidade, nem por isso ela logrou êxito em todas as suas intenções. Novas reformas, ainda que não possam evitar as velhas tensões entre direitos, garantias e princípios, podem focalizar a efetividade de determinados ditames, tornando verdadeiras regras os textos legais que a atual reforma não pôde tornar mais do que recomendações relativizáveis.

\section{CONSIDERAÇÕES FINAIS}

A pergunta que se procurou responder com esse artigo foi "em que medida os direitos humanos do acusado, previstos na Constituição Federal, estão sendo afetados 
pelas Leis $11.719 / 08$ e 11.689/08”? No caso brasileiro, conforme destacado na primeira seção, a temática dos direitos humanos como construção abstrata a ser incorporada em determinados diplomas legais, ganha destaque quando da ditadura militar e, em seguida, quando as primeiras movimentações para a elaboração da Constituição Federal de 1988. Se em um primeiro momento a expressão foi empregada principalmente por aqueles que buscavam a efetivação dos direitos humanos de primeira geração - políticos e civis - em um segundo momento ela passa a ser internalizada por todos que procuravam uma maior efetividade dos direitos sociais, econômicos e culturais. O resultado combinado desses dois movimentos foi a Carta constitucional de 1988, que estabeleceu a indivisibilidade dos direitos humanos, os quais se caracterizariam por sua unidade e interdependência.

À incorporação dos direitos humanos na Carta constitucional, seguiu-se o estudo desses pelas ciências sociais. De acordo com Soares e Guidani (2010), essas análises podem ser classificadas em três grupos principais: (1) os que apresentam os entendimentos contemporâneos de direitos humanos e reconhecem o seu valor à medida que sejam apropriados por grupos locais e convertidos em ferramentas de resistência cultural, política e social; (2) os que demonstram os resultados de pesquisas sobre as múltiplas formas de transgressão aos direitos humanos perpetradas no Brasil e no acompanhamento das lutas, empreendidas por movimentos sociais ou políticas públicas, pelo respeito aos direitos humanos; e (3) os que oferecem uma análise dos arranjos institucionais, transnacionais e nacionais associados à emergência dos direitos humanos como parâmetro político e normativo.

Em síntese: alguns desconfiam, mas valorizam; outros analisam os processos de formação e vocalização da demanda social e as respostas do Estado, ou seu protagonismo; e há os que focalizam dinâmicas institucionais ou impactos macro políticos derivados, seja da mobilização popular e da participação cidadã, seja de transformação nos marcos legais, nas estruturas institucionais e na redefinição de seu padrão de atuação (Soares e Guidani, 2010, p. 30).

A reforma do processo penal se insere na proposta de análise da transformação dos marcos legais, nas estruturas institucionais e na redefinição do padrão de atuação do sistema de justiça criminal para a forma de processamento dos crimes comuns e dos crimes dolosos contra a vida. Contudo, tal como destacado por Soares e Guidani, a lei em abstrato é quase sempre muito distinta da lei em operação, ou melhor, os efeitos esperados pela lei em abstrato nem sempre são os verificados quando da implantação da lei por seus operadores. Em parte isso ocorre porque o saber local, em boa medida, produz efeitos inesperados sobre o processo de administração do direito. 
$\mathrm{Na}$ segunda seção foram analisadas as seguintes alterações realizadas pelas leis 11.719/08 e 11.689/08, assim como sua interpretação jurisprudencial: (1) proibição do uso de algemas; (2) proibição da referência ao silêncio do réu em seu prejuízo; (3) extinção do protesto por novo júri; (4) fim do fracionamento da audiência; (5) identidade física do juiz no processo penal; (6) mutatio libelli; (7) emendatio libelli; (8) fundamentação da decisão de pronúncia; (9) extinção da prisão em decorrência da decisão da pronúncia; e (10) simplificação da quesitação do júri. Os resultados indicam que algumas das alterações almejadas pela reforma do processo penal realizada em 2008 ainda se inserem em pontos sensíveis da cultura jurídica local, e a linguagem polissêmica dos direitos fundamentais por vezes dá espaço para que interpretações discordantes das nossas tradições jurídicas e políticas sejam igualmente ouvidas.

Por um lado, no cenário de desigualdade social extrema característico do país, nossa justiça não poderia ser tão disponível às partes, pois elas podem estar em posições sociais tão desiguais que não viabilizariam manejar nada que ousasse ser chamada de justiça. Essa visão justificaria resquícios de um sistema inquisitorial que ainda teima em concentrar poderes nas mãos dos juízes, quando, por exemplo, ele mantém a faculdade de deferir ou não a produção de provas, de acordo com a utilidade ou necessidade destas à instrução criminal, ou quando mantém sua competência especial na emendatio libelli. Mas, por outro, a força opressiva do Estado também sempre se fez sentir aqui e a nossa confusão entre público no sentido de vontade geral e público no sentido de vontade do Estado não é absoluta. É essa outra face da moeda que justificaria os clamores pela efetivação de reformas que ampliam a autonomia das partes do processo, por exemplo, exigindo como parâmetro de medição de uma "duração razoável" seus efeitos negativos sobre o réu e não seus efeitos positivos sobre a busca da verdade pelo Estado.

Se o processo continua sendo um mecanismo de busca da verdade por um Estado que pode alcançá-la mais facilmente por sua liberdade perante os interesses particulares das partes, as partes continuam reclamando maior autonomia. Afinal, por estarem adstritas aos seus interesses particulares sabem melhor que o Estado o que seria o melhor para elas. Ainda não resta claro se a garantia do devido processo legal no Brasil, e demais direitos fundamentais que acompanham esse princípio, mesmo após as reformas, pende mais para uma prerrogativa do Estado ou um direito das partes.

Voltando às lições de Garapon e Papadopoulos (2008, p.10), temos que "a cultura não dita solução alguma - ela estabelece a tela de fundo conceitual sobre a qual os debates passam a ter sentido". O debate sobre os rumos do processo penal brasileiro, portanto, está aberto e a tela de fundo sobre a qual ele se desenrola, de acordo com o que foi dito anteriormente, se é "um retrato autêntico de um objeto obscuro, não pode ser claro, certamente terá de ser obscuro” (Wittgenstein apud Geertz, 2002, p. 325). 
Nesse contexto, o debate não está fechado nem no seu início, nem no seu final. E ele não está inteiramente nas mãos nem dos legisladores, nem dos juristas, nem dos operadores do direito, por mais que a responsabilidade desses últimos tenda a ser a maior. Na verdade, qualquer transformação do nosso processo terá de reunir a vontade política dessas três frentes sendo que, mais importante que a alteração legislativa e a interpretação teórica, será a sua efetivação nas mãos dos advogados, defensores, promotores e, especialmente, magistrados.

: ARTIGO APROVADO (02/12/2012) : RECEBIDO EM 17/04/2011

\section{NOTAS}

1 Exceções a essa regra são os artigos de Gustavo Henrique Badaró disponíveis no Boletim do IBCCRIM sobre problemas de direito intertemporal; novas justificativas inseridas por tais leis para rejeição da denúncia ou queixa e absolvição sumária; e, ainda, alguns critérios para balizar a forma de interpretação da regra da identidade física do juiz, inovação trazida pela referida reforma. A relação entre a produção doutrinária da reforma de 2008 (especialmente, no que diz respeito aos textos publicados pelo Boletim do IBCCRIM durante os anos de 2008 e 2010) e os julgados publicados no ano seguinte à mudança foi analisada por Ribeiro et al. (2010).

2 De acordo com matéria publicada no jornal Folha de São Paulo, em 9 nov. 2010, o Senado aprovou em votação simbólica e em primeiro turno, em 08/11/10, uma nova reforma do Código do Processo Penal brasileiro.

3 O Caso João Hélio refere-se ao crime ocorrido na noite de 7 de fevereiro de 2007. João Hélio tinha 6 anos de idade quando o carro em que ele estava com a mãe foi assaltado, e o menino, que ficou preso ao cinto de segurança, foi arrastado pelo lado de fora do veículo.

4 O caso Isabella Nardoni refere-se ao crime ocorrido em 29 de março de 2008. Isabella Nardoni tinha 5 anos de idade quando foi defenestrada do sexto andar de um condomínio de luxo (em São Paulo) por seu pai e sua madrasta.

5 Art. $60, \S 4^{\circ}$, inc. IV: "Não será objeto de deliberação a proposta de emenda tendente a abolir os direitos e garantias fundamentais".

6 É interessante destacar que, de acordo com a doutrina processualística penal, o CPP de 1941, por ter sido uma legislação publicada durante um regime autoritário, padece desses mesmos problemas. Assim, uma vez que o Código, elaborado sob a égide e os influxos autoritários do Estado Novo e considerando o fato de que, vinte anos após a publicação da chamada "Constituição Cidadã", o Brasil pode ser considerado como uma democracia em fase de consolidação, faz-se indispensável adequar os dois dispositivos legais. Em última instância, este foi o objetivo maior da reforma de 2008.

7 Inserido pela Lei 11.689/08 através do art. 474, §3 “Não se permitirá o uso de algemas no acusado durante o período em que permanecer no plenário do júri, salvo se absolutamente necessário à ordem dos trabalhos, à segurança das testemunhas ou à garantia da integridade física dos presentes".

8 Inserido pela Lei 11.689/08 através do art. 478, inc. II: "Durante os debates as partes não poderão, sob pena de nulidade, fazer referências: II - ao silêncio do acusado ou à ausência de interrogatório por falta de requerimento, em seu prejuízo". 
9 Retirado do Código de Processo Penal através da Lei 11.689/08, que revogou o art. 607 - "O protesto por novo júri é privativo da defesa, e somente se admitirá quando a sentença condenatória for de reclusão por tempo igual ou superior a 20 (vinte) anos, não podendo em caso algum ser feito mais de uma vez".

10 Inserido no Código de Processo Penal a partir da nova redação concedida aos arts. 400 e 411.

"Art. 400. Na audiência de instrução e julgamento, a ser realizada no prazo máximo de 60 dias, proceder-se-á à tomada de declarações do ofendido, à inquirição das testemunhas arroladas pela acusação e pela defesa, nessa ordem, ressalvado o disposto no art. 222 deste Código, bem como aos esclarecimentos dos peritos, às acareações e ao reconhecimento de pessoas e coisas, interrogando-se, em seguida, o acusado.”

“Art. 411. Na audiência de instrução, proceder-se-á à tomada de declarações do ofendido, se possível, à inquirição das testemunhas arroladas pela acusação e pela defesa, nesta ordem, bem como aos esclarecimentos dos peritos, às acareações e ao reconhecimento de pessoas e coisas, interrogando-se, em seguida, o acusado e procedendo-se o debate."

11 Art. $400 . \S 1^{\circ}$, As provas serão produzidas numa só audiência, podendo o juiz indeferir as consideradas irrelevantes, impertinentes ou protelatórias.

12 O embasamento jurisprudencial do presente artigo recorre ao levantamento de julgados feito na realização da pesquisa Pensando o Direito: uma análise das alterações produzidas pelas leis 11.719/08 e 11.689/08. Essa pesquisa foi executada pelo Centro de Estudos de Segurança e Cidadania (CESeC) da Universidade Candido Mendes (Ucam), a partir do financiamento da Secretaria de Assuntos Legislativos (SAL) do Ministério da Justiça (MJ). As decisões citadas são alguns exemplos desse quadro jurisprudencial coletado no momento de realização da pesquisa.

13 Inserida no Código de Processo Penal através da Lei 11.719/08, que estabeleceu em seu art. 399, $\$ 2^{\circ}$, o seguinte: "O juiz que presidiu a instrução deverá proferir a sentença”.

14 Art. 383: "O juiz, sem modificar a descrição do fato contida na denúncia ou queixa, poderá atribuir-lhe definição jurídica diversa, ainda que, em consequência, tenha de aplicar pena mais grave”.

15 Neste sentido, ALVES, Jamil Chaim e BURRI, Juliana, Emendatio e mutatio libelli de acordo com a lei 11.719/08. Disponível em: www.ibccrim.org.br. Publicado em: 20 jun. 2009.

16 “Art. 413, $\S 3^{\circ}$ : O juiz decidirá, motivadamente, no caso de manutenção, revogação ou substituição de prisão ou medida restritiva de liberdade anteriormente decretada e, tratando-se de acusado solto, sobre a necessidade da decretação da prisão ou imposição de quaisquer medidas previstas no Título IX do Livro I deste Código.”

17 Idem, ibidem.

18 Como a data da publicação acusa, nesse ponto Nucci analisava ainda a proposta de reforma ainda em discussão.

\section{REFERÊNCIAS BIBLIOGRÁFICAS}

ABRAMOVAY, Pedro. Apresentação das reformas no processo penal. In: MOURA, Maria Thereza Rocha de Assis. As reformas no processo penal. São Paulo: Revista dos Tribunais, 2008.

ALEXY, Robert. Tres escritos sobre los derechos fundamentales y la teoria de los principios. Universidad Externado de Colombia, 2003.

ALMEIDA, Suely. Violência e direitos humanos no Brasil. Praia Vermelha, n. 11, $2^{\circ}$ sem. 2004.

ARENDT, Hanna. As Origens do totalitarismo. Rio de Janeiro: Documentário, 1979.

BANDEIRA, Katherine Lages Contasti. O "positivismo" social e a cultura da agressividade: a punição como fundamentação da prisão. Revista da Esmape, v. 12, n. 25, jan./jun., 2007.

BARROCO, Maria Lúcia Silva. Serviço Social, ética e direitos humanos. Praia Vermelha, n. 11, $2^{\circ}$ sem. 2004. BOBBIO, Norberto. Era dos direitos. Rio de Janeiro: Campus, 1988.

CARDIA, Nancy; ADORNO, Sérgio; POLETO, Frederico. Homicídio e violação de direitos humanos em São Paulo. Estudos Avançados, v. 17, n. 47, jan./abr. 2003. 
CARVAlHO, José Murilo. Cidadania no Brasil: o longo caminho. Rio de Janeiro: Civilização Brasileira, 2004.

COSTA, Sérgio. Democracia cosmopolita: déficits conceituais e equívocos políticos. Revista Brasileira de Ciências Sociais, v. 1, 2005.

DWORKIN, Ronald. O império do direito. São Paulo: Martins Fontes, 2003.

GARAPON, Antoine; PAPADOPOULOS, Ioannis. Julgar nos Estados Unidos e na França: cultura jurídica francesa e common law em uma perspectiva comparada. Rio de Janeiro: Lumen Juris, 2008.

GEERTZ, Clifford. O saber local: fatos e leis em uma perspectiva comparada. In: GEERTZ, Clifford. O saber local. Petrópolis: Vozes, 2002, p. 249-356.

GRINOVER, Ada Pellegrini. Anteprojetos de lei de reforma do código de processo penal: entregues ao Ministro da Justiça em 6 de dez. 2000. [2000]. Disponível em:

<www.tj.ro.gov.br/emeron/sapem/2001/outubro/2610/LEGISLA\%C3\%87\%C3\%83O/L01.htm>.

HOLLANDA, Cristina Buarque. Polícia e direitos humanos: política de segurança pública no primeiro governo Brizola (Rio de Janeiro: 1983-1986). Rio de Janeiro: Revan, 2005.

KANT DE LIMA, Roberto. Direitos civis e direitos humanos: uma tradição judiciária pré-republicana? São Paulo em Perspectiva, v. 18, n. 1, p. 49-59, 2004.

MARSHALL, T. H. Cidadania e classe social. In: MARSHALL, T. H. Cidadania, classe social e status. Rio de Janeiro, Zahar, 1967, p. 57-114.

NUCCI, Guilherme de Souza. Júri: princípios constitucionais. São Paulo: Editora Juarez de Oliveira, 1999.

NUNES, Walter. Reforma do Código de Processo Penal: Leis n. 11.689, n. 11.690 e n. 11.719, de 2008.

Instituto Brasileiro de Direito Processual, dez. 2008.

PASSOS, Edilenice. Código de Processo Penal: notícia histórica sobre as comissões anteriores. Brasília, Senado Federal: Secretaria de Informação e Documentação, 2008.

PIOVESAN, Flávia. Ações afirmativas da perspectiva dos direitos humanos. Cadernos de Pesquisa, v. 35, n. 124, jan./abr. 2005.

REIS, Rossana Rocha. Os direitos humanos e a política internacional. Revista de Sociologia e Política, n. 27, 2006. RIBEIRO, Ludmila; MACHADO, Igor Suzano; SILVA, Klarissa. Pensando o direito - Os novos procedimentos penais. Pensando o Direito, v. 23, p. 1-90, 2010

SANTOS, Wanderley Guilherme dos. Cidadania e justiça: a política social na ordem brasileira. Rio de Janeiro: Editora Campus, 1979.

SOARES, Luiz Eduardo; GUIDANI, Miriam. Direitos humanos e ciências sociais no Brasil. In: MARTINS, Carlos Benedito; LESSA, Renato. Horizontes das ciências sociais no Brasil: ciência politica. São Paulo: Anpocs, 2010.

SOUZA, Jessé. A construção social da subcidadania: para uma sociologia política da modernidade periférica. Belo Horizonte: Editora UFMG; Rio de Janeiro: IUPERJ, 2003.

ZALUAR, Alba. Democracia inacabada: o fracasso da segurança pública. Estudos Avançados, v. 21, 2007.

Universidade Federal de Minas Gerais Faculdade de Filosofia e Ciências Humanas Av. Antônio Carlos, n. 6627 - sala 4208 Campus Pampulha - 31270-901 Belo Horizonte - MG - Brasil ludmila.ribeirolgmail.com

\section{Ludmila Mendonça Lopes Ribeiro}

\author{
Professora adjunta do Departamento de Sociologia e \\ ANTROPOLOGIA E PESQuisadoRA DO CENTRO DE ESTUdOS DE \\ Criminalidade e Segurança Pública na UFMG \\ DOUTORA EM SOCIOLOGIA PELO INSTITUTO UNIVERSITÁRIO DE \\ PESquisas do RiO dE JANEIRO \\ Mestre em Administração Pública pela \\ Fundação JoÃo PINHEIRO
}


702 : A REFORMA PROCESSUAL PENAL DE 2008 E A EFETIVAÇÃO DOS DIREITOS HUMANOS DO ACUSADO

\section{Klarissa Almeida}

Universidade Federal do Rio de Janeiro Instituto de Filosofia e Ciências Sociais Largo de São Francisco, 1 - grupo 109, sala 405 Centro - 22050-070 Rio de Janeiro - RJ - Brasil silva.klarissalagmail.com

Universidade Federal de Viçosa Departamento de Ciências Sociais Avenida Ph Rolfs, s/n Campus Universitário - 36570-000 Viçosa - MG - Brasil igorsuzanolamail.com
Doutoranda Em CIÊnCIAS Humanas/SOCIOLOgIA, no Programa DE Pós-Graduação em Sociologia e Antropologia da UFRJ Cientista Social e Mestre em Sociologia pela UFMg Pesquisadora do Núcleo de Estudos da Cidadania, CONFLITO E VIOLÊNCIA DA UFRJ

\section{Igor Suzano Machado}

DOUTOR EM SOCIOLOGIA PELO INSTITUTO DE Estudos Sociais e Políticos da UERJ Mestre EM SOCIOLOGIA PELO INSTITUTO UniVERSITÁRIO de Pesquisas do Rio de Janeiro DOUTORANDO EM SOCIOLOGIA PELO INSTITUTO Universitário de Pesquisas do RIO dE JANEIRO 